\title{
Review Article \\ Cost Effectiveness of Vacuum-Assisted Closure and Its Modifications: A Review
}

\author{
Akhlak Hussain, Kuldip Singh, and Mohinder Singh \\ Department of Surgery, Government Medical College, Patiala 147001, India \\ Correspondence should be addressed to Akhlak Hussain; akku5658@gmail.com
}

Received 20 November 2012; Accepted 30 December 2012

Academic Editors: E. Raposio, H. Terashi, and J. Y. Yang

Copyright (C) 2013 Akhlak Hussain et al. This is an open access article distributed under the Creative Commons Attribution License, which permits unrestricted use, distribution, and reproduction in any medium, provided the original work is properly cited.

Negative topical pressure, the general category to which the trademarked VAC therapy belongs, is not a new concept in wound therapy. It is also called subatmospheric pressure therapy, vacuum sealing, vacuum-assisted closure therapy, vacuum pack therapy, and sealing aspirative therapy. The VAC therapy system is trademarked by Kinetic Concepts, Inc., or KCI. It was first reported in 1997. The aim of the procedure is to use negative pressure to create suction, which drains the wound of exudate (i.e., fluid, cells, and cellular waste that has escaped from blood vessels and seeped into tissue) and influences the shape and growth of the surface tissues in a way that helps healing. Negative-pressure therapy for the closure of wounds accelerates secondary wound healing. High cost is still a hindrance in its use in developing nations. Many modifications were tried, but their efficacy is yet to be proved. In reality, this method is quite cost effective. It is only the lack of understanding and adequate setup which makes this method hard to use. The main objective of this paper is to focus on the cost effectiveness of VAC and its modifications. We want to emphasize the importance of homemade NPT and the use of simple suction devices.

\section{Introduction}

Chronic wound management represents a considerable burden on health services and requires considerable manpower, frequent specialist consultation, and adjunct therapies. The negative pressure wound therapy (NPWT) is an important adjunct, which offers an important option for the advanced management of many wound types [1-3]. Currently NPWT has become an established method of wound management. Most of reports used the foam-based NPWT system using commercially available devices (e.g., KCI's VAC). These are affordable and easily available in developed nations. But in developing countries, where the proportion of poor patients is very high, it is still beyond the reach of the needy patients. Some tried to reduce cost using other cheaper suction devices. Taking inspiration from such efforts, we are also trying one of the cheaper options for the betterment of patients and our observations were satisfactory. Thus, the importance of such methods is highlighted to enhance more research in this field so that the prolonged misery of chronic as well as acute wounds can be shortened in minimal cost.

\section{Evidence behind Cost Effectiveness}

NPWT benefits include rapid wound granulation, epithelialisation and contraction [4], reduction in frequency of dressing changes [5], reduced infection risk [6], reduced treatment costs [7], control of exudate [8], concurrent rehabilitation [9], and better patient tolerance [10].

The first description of the NPWT in a series of patients was given by Fleischmann et al. in 1993 [26]. The efficacy of NPWT was initially described by Morykwas et al. and Morykwas [27, 28]. There is a substantial literature on NPWT including reports of both comparative and noncomparative clinical studies, case studies, economic analyses, literature reviews, and technology assessments. Most studies demonstrate the superior or at least the same efficacy as compared to the conventional wounds management. But due to heterogeneity in types, sites and duration of wounds the results cannot be generalized. After a thorough literature search, we concluded that NPWT is efficacious and cost effective method of wound management not only in chronic but also for acute wounds (Table 1). 
TABLE 1: (a) Nonrandomized studies. (b) Randomized studies. (c) Meta-analysis: the heterogeneity of the patients treated with NPWT makes it difficult to compare between different studies [11].

(a)

\begin{tabular}{|c|c|c|c|}
\hline S. no. & Study & Comparator & Inferences \\
\hline (1) & $\begin{array}{l}\text { Philbeck et al., [12] versus } \\
\text { Ferrell et al., [13] }\end{array}$ & $\begin{array}{l}\text { Saline gauze dressing } \\
\text { and pressure relief bed }\end{array}$ & Faster closure rate and healing but lesser overall cost \\
\hline (2) & Phillips and Rao [14] & Saline dressing & Fewer nursing hours but slight more costs \\
\hline (3) & Luckraz et al., [15] & $\begin{array}{l}\text { Sternal rewiring + closed } \\
\text { irrigation }\end{array}$ & Lesser overall cost \\
\hline$(4)$ & Herscovici et al., [16] & Wet to dry dressing & Effective but similar cost \\
\hline
\end{tabular}
(b)

\begin{tabular}{lcc}
\hline S. no. & Study & Comparator \\
\hline & & \\
(1) & Mouës et al., [5] & Standard moist gauze \\
& & therapy
\end{tabular}

Inferences

Hydrocolloids, alginate, acetic acid, and sodium hypochlorite Vuerstaek et al., [17]

Conventional wound care Lavery et al., [18] Apelqvist et al., [19] Mody et al., [20] Flack et al., [21]
Significantly higher material expenses $(P<0.0001)$, but significantly lower nursing expenses $(P<0.043)$ and lower hospitalization costs $(P<0.043)$. There was no significant difference in total costs per patient between the two therapies.

NPWT had faster healing and greater wound size reduction and lesser time investment $(P=0.3$ and $P=0.83, P=0.04$, resp.). Total costs were in favour of the dressings group, however, insignificant $(P=0.09)$ [8]. Although NPWT instruments and dressings are more expensive, their longer application on wounds and less-frequent changing will reduce the total cost and the labour power and positively impacting on productivity.

Quicker healing, faster wound preparation for grafting, and reduced costs with NPWT ( $P=0.001, P=0.005, P=0.001$, resp.); the major part of this cost difference was due to higher personnel costs and longer hospital stay in the dressings group caused by the slower healing. Both groups showed significant increase in patients' QoL and decrease in pain scores.

TNP improved successful wound treatment outcome for diabetic foot ulcers and might reduce resource utilization

NPWT resulted in lower resource utilization and a greater proportion of patients obtaining wound healing at a lower overall cost of care Inexpensive materials can be utilized for TNP wound closure in a developing country.

V.A.C. therapy was more effective and less expensive for patients with Type 1 and Type 2 diabetes

Although costlier, the HM-VAC should be considered in underdeveloped countries as the healing is significantly faster. (c)

\begin{tabular}{lll}
\hline S. no. & Study & Trials included \\
\hline
\end{tabular}

Vikatmaa et al., [23]

14 RCTs

Ubbink et al., [24]

13 RCTs

Birke-Sorensen et al., [25]
Systematic review

Inferences

NPWT was at least as effective and in some cases more effective than the control treatment. NPWT to be a safe treatment, and serious adverse events have been rarely reported.

NPWT is efficient in treating wounds with improved clinical outcomes and should stimulate the healthcare system to provide such services and prevent it being obstructed by financial constraints. There is relatively weak evidence on which to base recommendations for any one NPWT treatment variable over another. There is a requirement of developing an international consensus for NPWT recommendations and treatment variables.

\section{Literature Search of Manually Powered Negative Pressure Devices}

No doubt, manually powered vacuum devices are much more cheaper than commercially available devices. The devices using normal suction apparatus are also cheaper but cannot be used in community setting. Although more systemic studies are required to prove effectiveness of these manually powered devices such as vacuum drains, but there is no doubt that these are much cheaper, easy to handle and any body 


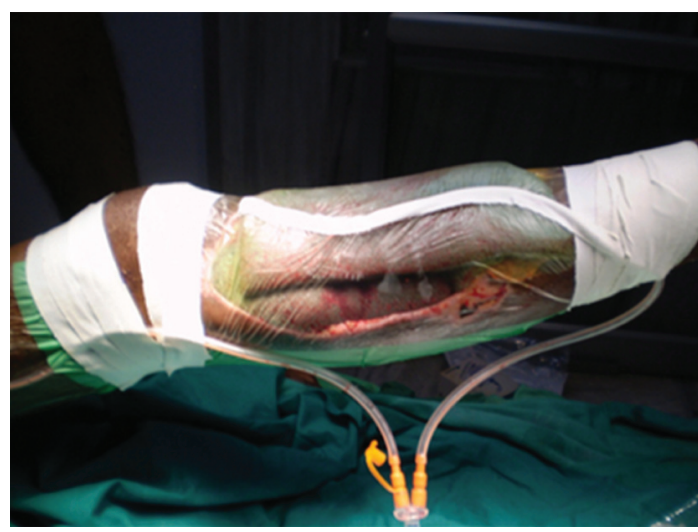

FIGURE 1: Singh et al's NPWT using constant suction with Romovac drain for 24 hours.

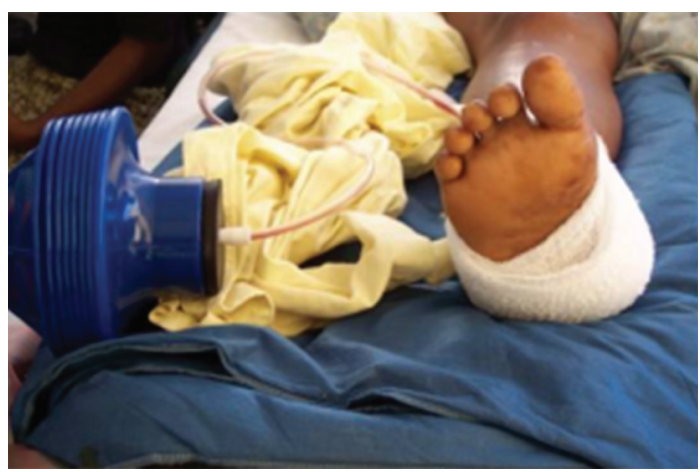

FIGURE 2: Mody et al.s NPWT device on traumatic foot wound. Occlusive dressing with integrated tubing is protected by gauze wrap.

can operate them after minimal training. Thus, they are very suitable to be used at home, avoiding hospital stay and in cases of mass casualties.

To the best of our knowledge, there are limited studies on dressings with manually operated vacuum devices. Singh et al. performed NPWT using Romovac or similar $18 \mathrm{fr}$ drain. Seven patients with complex wounds were treated with alternate vacuum suction dressing. The dressing was applied 24 hours after surgical debridement of necrotic tissue (Figure 1). After few modifications, they obtained gratifying results. Specific results were no given. They described it to be a simple and effective method of NPWT which should benefit the larger population where the standard equipment is not available [29].

Mody et al. used a bellows which generated $75 \mathrm{mmHg}$ negative pressure and has to be compressed every 8 hours (Figure 2). They applied it on 24 patients with 26 wounds. They described it to be safe and feasible for use in low resource settings. It costs only $\$ 3$ and light, weighing only half a pound. The clinical efficacy and efficaciousness would be studied in subsequent trials [30].

Through this paper the necessity of more refinement in cheaper NPWT is emphasized. In sequence we are also using the same kind of device as described by Singh et al. We are

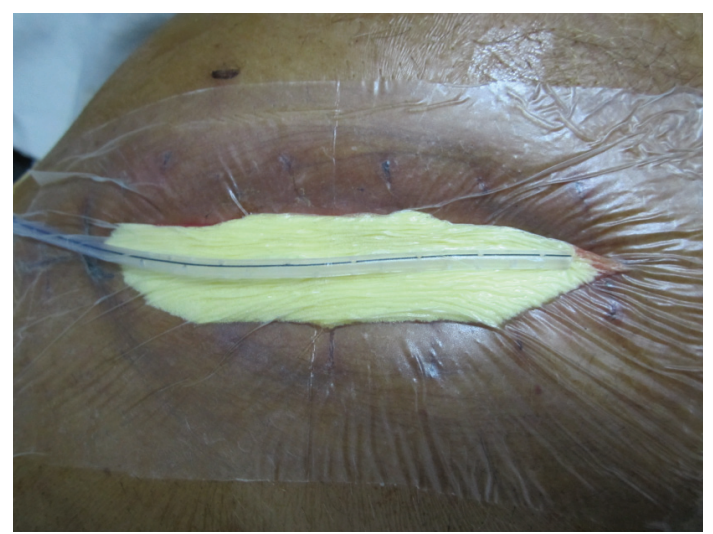

FIGURE 3: NPWT using simple vacuum drain on a post cholecystectomy SSI.

using poly urethane foam dressing, after twice autoclaving, opposite covering and constant suction by Romovac or JP drains for 48 hours (Figure 3). We applied this dressing on 4 cases of postoperative surgical site infections and obtained very motivating results. One of our infected mesh repair healed within 30 days without removing the mesh.

We observe the following advantages of such kinds of device:

(i) easy to handle

(ii) hospital admission not required

(iii) good patient compliance and satisfaction

(iv) require minimal training to maintain vacuum at home

(v) can be applied to many cases at a time

(vi) give adequate mobility to the patient.

The difficulties faced are a follows:

(i) cannot be applied on highly uneven body surfaces

(ii) proper occlusion is difficult to maintain in warm conditions due to sweating

(iii) drain require fixation.

Due to the fewer number of cases, the efficacy cannot be commented. But the results were highly satisfactory in such that kind of government set where most of the patients are poor and funding is limited preventing the use of commercial devices. We suggest further studies to settle down the matter of efficacy and to develop proper guidelines.

\section{Conclusion}

NPWT is often perceived to be more expensive than advanced wound care. However, this perception may be based more on unit price considerations than on a comparison of the total treatment cost. Wider use of NPWT in wound management is a potential way to save money, providing at least the same quality of care as conventional methods. A large number of studies within a very short time of 
NPWT evolution have provoked national and international committees to develop NPWT wound care guidelines. This should encourage the government to conduct studies to validate these results with implemented local evaluations and audits to support widespread adoption of NPWT in national wound care. All patients should be assessed on an individual basis and have equality impact and risk assessments to ensure that every patient has the opportunity to benefit from NPWT, which is a valuable addition, if used appropriately to specific patients' case and health care provider experience. NPWT has evolved from large devices to smaller, more portable devices, which can allow a smoother transition from hospital to community. Evidence on the cost effectiveness of TNP is necessarily limited, because of the lack of robust clinical effectiveness evidence. It was confined to only few types of wounds and usually related to only one manufacturer's product.

\section{Abbreviations}

KCI: Kinetic concepts inc.

NPWT: Negative pressure wound therapy

TNP: Topical negative pressure

SSI: $\quad$ Surgical site infections.

\section{References}

[1] P. E. Banwell and L. Téot, "Topical negative pressure (TNP): the evolution of a novel wound therapy," Journal of Wound Care, vol. 12, no. 1, pp. 22-28, 2003.

[2] M. J. Morykwas, J. Simpson, K. Punger, A. Argenta, L. Kremers, and J. Argenta, "Vacuum-assisted closure: state of basic research and physiologic foundation," Plastic and Reconstructive Surgery, vol. 117, no. 7, pp. 121S-126S, 2006.

[3] V. Henderson, J. Timmons, T. Hurd, K. Deroo, S. Maloney, and S. Sabo, "NPWT in everyday practice made easy," Wounds International, vol. 1, no. 5, pp. 1-6, 2010.

[4] D. G. Armstrong and L. A. Lavery, "Negative pressure wound therapy after partial diabetic foot amputation: a multicentre, randomised controlled trial," The Lancet, vol. 366, no. 9498, pp. 1704-1710, 2005.

[5] C. M. Mouës, G. J. van den Bemd, W. J. Meerding, and S. E. Hovius, "An economic evaluation of the use of TNP on fullthickness wounds," Journal of Wound Care, vol. 14, no. 5, pp. 224-227, 2005.

[6] B. E. Leininger, T. E. Rasmussen, D. L. Smith, D. H. Jenkins, and C. Coppola, "Experience with wound VAC and delayed primary closure of contaminated soft tissue injuries in Iraq," Journal of Trauma, vol. 61, no. 5, pp. 1207-1211, 2006.

[7] J. Apelqvist, D. G. Armstrong, L. A. Lavery, and A. J. M. Boulton, "Resource utilization and economic costs of care based on a randomized trial of vacuum-assisted closure therapy in the treatment of diabetic foot wounds," The American Journal of Surgery, vol. 195, no. 6, pp. 782-788, 2008.

[8] A. Braakenburg, M. C. Obdeijn, R. Feitz, I. A. L. M. Van Rooij, A. J. Van Griethuysen, and J. H. G. Klinkenbijl, "The clinical efficacy and cost effectiveness of the vacuum-assisted closure technique in the management of acute and chronic wounds: a randomized controlled trial," Plastic and Reconstructive Surgery, vol. 118, no. 2, pp. 390-397, 2006.
[9] C. A. Park, A. J. Defranzo, M. W. Marks, and J. A. Molnar, "Outpatient reconstruction using integra* and subatmospheric pressure," Annals of Plastic Surgery, vol. 62, no. 2, pp. 164-169, 2009.

[10] T. Hurd, P. Chadwick, J. Cote, J. Cockwill, T. R. Mole, and J. M. Smith, "Impact of gauze-based NPWT on the patient and nursing experience in the treatment of challenging wounds," International Wound Journal, vol. 7, no. 6, pp. 448-455, 2010.

[11] G. Neubauer and R. Ujlaky, "The cost-effectiveness of topical negative pressure versus other wound-healing therapies," Journal of Wound Care, vol. 12, no. 10, pp. 392-393, 2003.

[12] T. E. Philbeck, K. T. Whittington, M. H. Millsap, R. B. Briones, D. G. Wight, and W. J. Schroeder, "The clinical and cost effectiveness of externally applied negative pressure wound therapy in the treatment of wounds in home healthcare Medicare patients," Ostomy/Wound Management, vol. 45, no. 11, pp. 41-50, 1999.

[13] B. A. Ferrell, D. Osterweil, and P. Christenson, "A randomized trial of low-air-loss beds for treatment of pressure ulcers," Journal of the American Medical Association, vol. 269, no. 4, pp. 494-497, 1993.

[14] D. E. Phillips and S. J. Rao, "Negative pressure therapy in the community: analysis of outcomes," Wound Care in Canada, vol. 2, no. 1, pp. 42-45, 2003.

[15] H. Luckraz, F. Murphy, S. Bryant, S. C. Charman, and A. J. Ritchie, "Vacuum-assisted closure as a treatment modality for infections after cardiac surgery," Journal of Thoracic \& Cardiovascular Surgery, vol. 125, no. 2, pp. 301-305, 2003.

[16] D. Herscovici Jr., R. W. Sanders, J. M. Scaduto, A. Infante, and T. DiPasquale, "Vacuum-assisted wound closure (VAC therapy) for the management of patients with high-energy soft tissue injuries," Journal of Orthopaedic Trauma, vol. 17, no. 10, pp. 683-688, 2003.

[17] J. D. D. Vuerstaek, T. Vainas, J. Wuite, P. Nelemans, M. H. A. Neumann, and J. C. J. M. Veraart, "State-of-the-art treatment of chronic leg ulcers: a randomized controlled trial comparing vacuum-assisted closure (V.A.C.) with modern wound dressings," Journal of Vascular Surgery, vol. 44, no. 5, pp. 1029-1037, 2006.

[18] L. A. Lavery, A. J. Boulton, J. A. Niezgoda, and P. Sheehan, "A comparison of diabetic foot ulcer outcomes using negative pressure wound therapy versus historical standard of care," International Wound Journal, vol. 4, no. 2, pp. 103-139, 2007.

[19] J. Apelqvist, D. G. Armstrong, L. A. Lavery, and A. J. M. Boulton, "Resource utilization and economic costs of care based on a randomized trial of vacuum-assisted closure therapy in the treatment of diabetic foot wounds," The American Journal of Surgery, vol. 195, no. 6, pp. 782-788, 2008.

[20] G. N. Mody, I. A. Nirmal, S. Duraisamy, and B. Perakath, "A blinded, prospective, randomized controlled trial of topical negative pressure wound closure in India," Ostomy Wound Management, vol. 54, no. 12, pp. 36-46, 2008.

[21] S. Flack, J. Apelqvist, M. Keith, P. Trueman, and D. Williams, "An economic evaluation of VAC therapy compared with wound dressings in the treatment of diabetic foot ulcers," Journal of Wound Care, vol. 17, no. 2, pp. 71-78, 2008.

[22] D. Perez, M. Bramkamp, C. Exe, C. von Ruden, and A. Ziegler, "Modern wound care for the poor: a randomized clinical trial comparing the vacuum system with conventional saline-soaked gauze dressings," The American Journal of Surgery, vol. 199, no. 1, pp. 14-20, 2010. 
[23] P. Vikatmaa, V. Juutilainen, P. Kuukasjärvi, and A. Malmivaara, "Negative pressure wound therapy: a systematic review on effectiveness and safety," European Journal of Vascular and Endovascular Surgery, vol. 36, no. 4, pp. 438-448, 2008.

[24] D. T. Ubbink, S. J. Westerbos, E. A. Nelson, and H. Vermeulen, "A systematic review of topical negative pressure therapy for acute and chronic wounds," British Journal of Surgery, vol. 95, no. 6, pp. 685-692, 2008.

[25] H. Birke-Sorensen, M. Malmsjo, P. Rome et al., "Evidencebased recommendations for negative pressure wound therapy: treatment variables (pressure levels, wound filler and contact layer) steps towards an international consensus," Journal of Plastic, Reconstructive \& Aesthetic Surgery, vol. 64, no. 1, pp. S1-S16, 2011.

[26] W. Fleischmann, W. Strecker, M. Bombelli, and L. Kinzl, "Vacuum sealing for treatment of soft tissue injury in open fractures," Unfallchirurg, vol. 96, no. 9, pp. 488-492, 1993.

[27] M. J. Morykwas, L. C. Argenta, E. I. Shelton-Brown, and W. McGuirt, "Vacuum-assisted closure: a new method for wound control and treatment: animal studies and basic foundation," Annals of Plastic Surgery, vol. 38, no. 6, pp. 553-562, 1997.

[28] M. J. Morykwas, "External application of sub-atmospheric pressure and healing: mechanisms of action," Wound Healing Society Newsletter, vol. 8, pp. 4-5, 1998.

[29] M. Singh, R. Singh, S. Singh, V. Pandey, and D. Singh, "Vacuum assisted closure in wound management-Poor man's VAC@)," The Internet Journal of Plastic Surgery, vol. 6, no. 1, 2009.

[30] G. N. Mody, D. R. Zurovcik, G. Kansayisa et al., "Phase I Results of a Simplified Negative Pressure Wound Therapy Device for Use in Low Resource Settings," 2011, http://clinicaltrials.gov/ct2/show/NCT01339429, http://www.technologyreview.com/biomedicine/24837/page1/. 


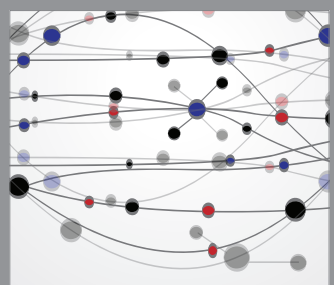

The Scientific World Journal
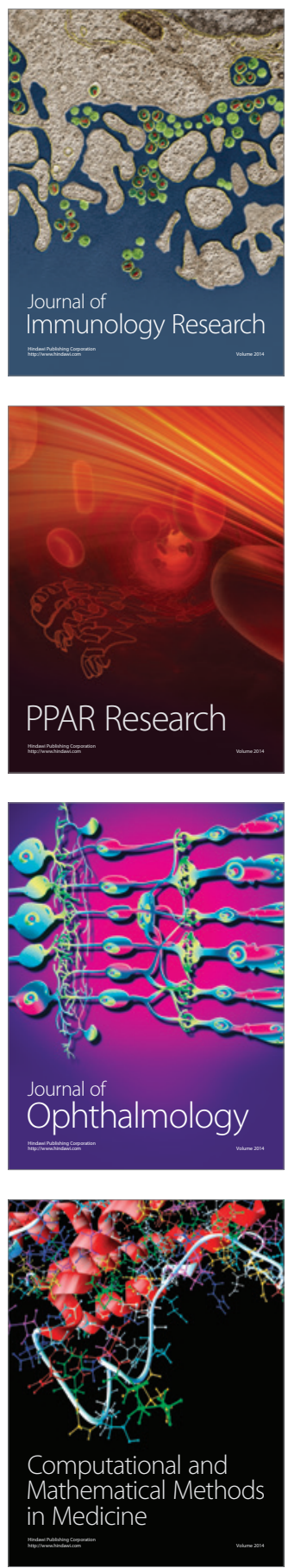

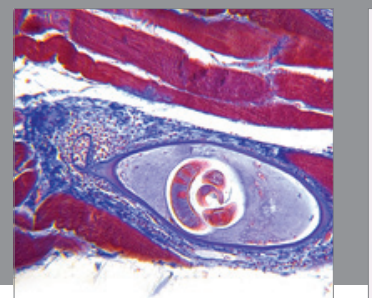

Gastroenterology

Research and Practice
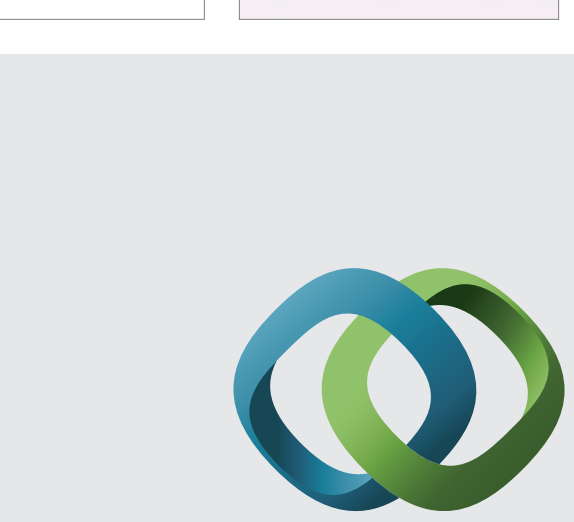

\section{Hindawi}

Submit your manuscripts at

http://www.hindawi.com
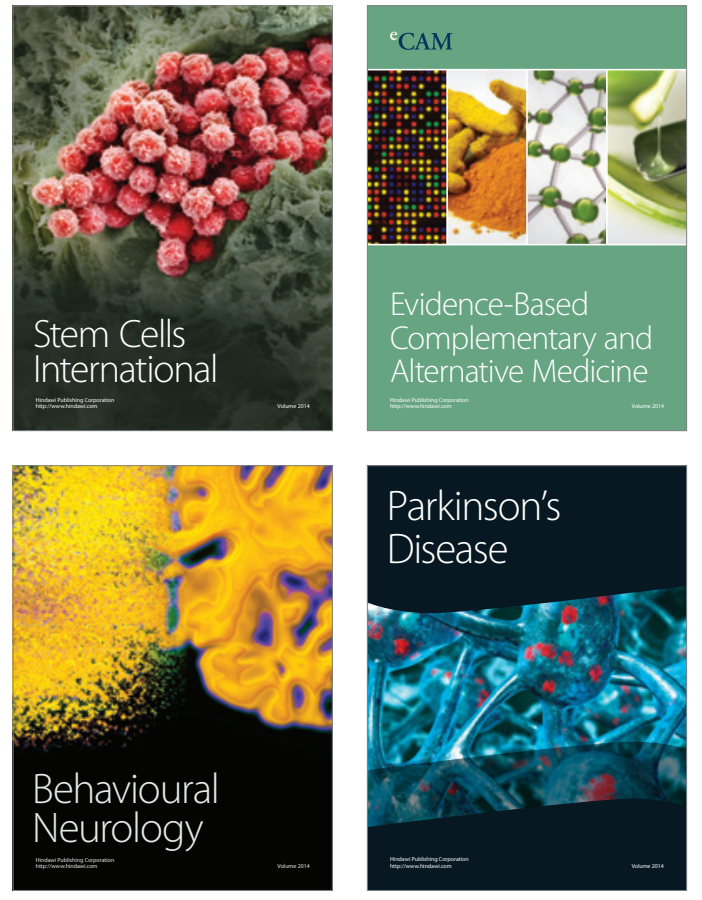
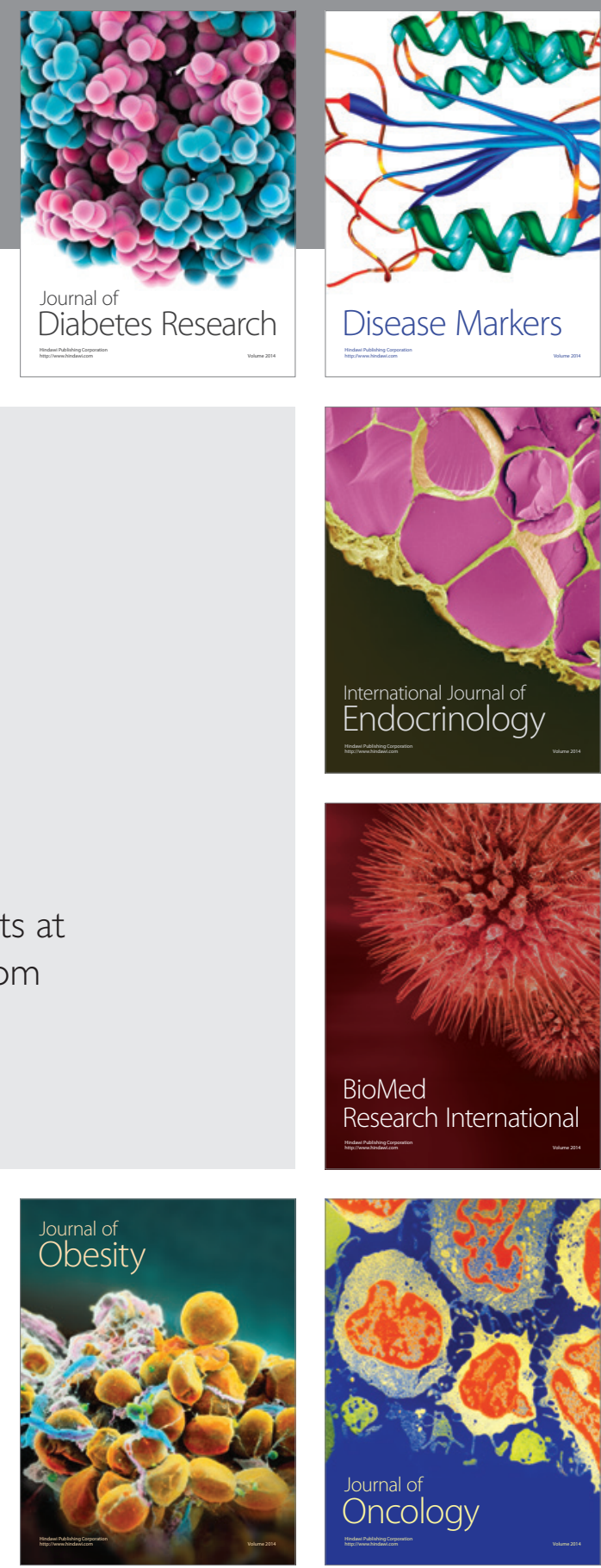

Disease Markers
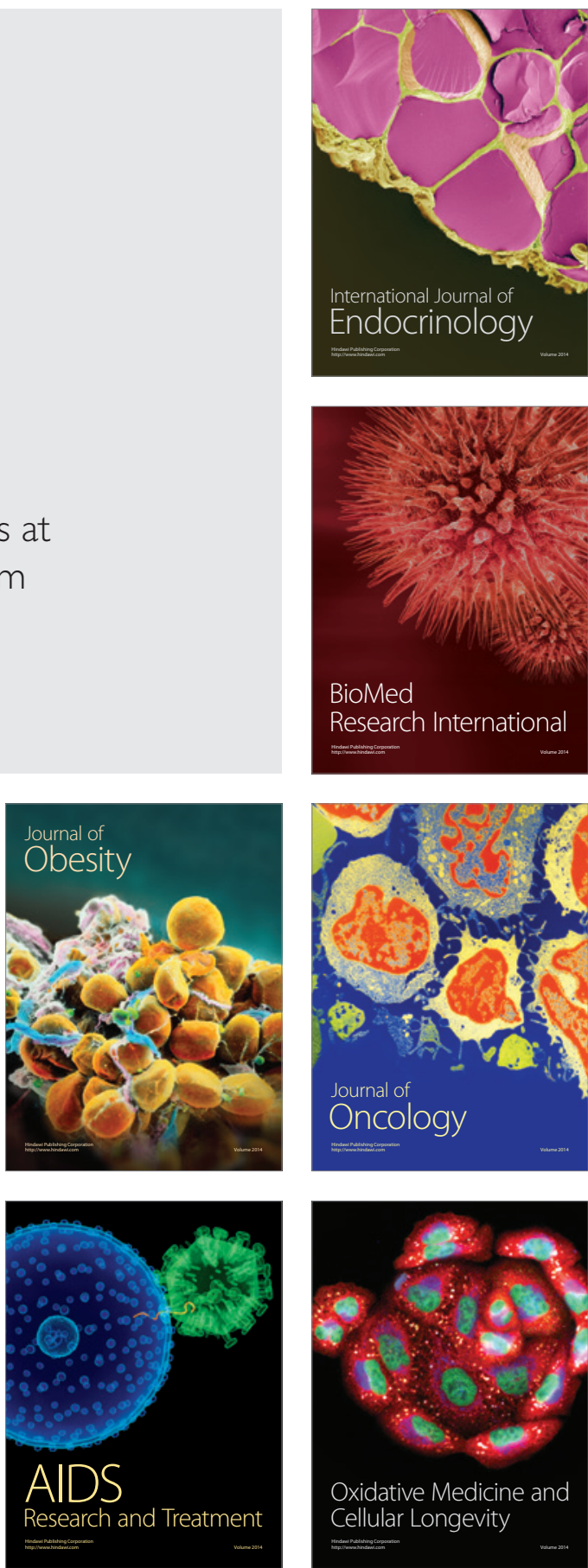